\title{
Agglomeration and assemblage: Deterritorializing urban theory
}

\author{
Abstract \\ In two recent papers Storper and Scott have sought to counter the rise of assemblage thinking in urban studies, \\ suggesting it is indeterminate, jargon-ridden and particularist - that it lacks a critique of power. Against such \\ approaches they propose the 'nature of cities' as an 'urban land nexus' driven by the economics of \\ agglomeration. In this paper we respond, largely agreeing on jargon yet arguing that assemblage is a form of \\ critical urban thinking that holds potential for a general but open theory of urbanity. We also suggest that many \\ parts of Scott and Storper's own work are entirely compatible with assemblage thinking, including concepts \\ such as urban 'bundling' and 'buzz'. Agglomeration theory explains why cities emerge and grow where they do \\ but is weak on issues of scale and morphology. Assemblage thinking embodies capacities to expand urban \\ studies through a better engagement with multi-scale relations, gearing the economics of agglomeration to the \\ study of urban morphology; understanding cities in terms of their possible futures as well as actual conditions. \\ We call for more open and productive interfaces between research disciplines and approaches - a \\ deterritorialization of urban theory. The choice is not between agglomeration and assemblage, it is between the \\ singular and the multiple.
}

\section{Keywords}

agglomeration, assemblage, morphology, multi-scale thinking, urban theory 


\section{Introduction}

Agglomeration is the basic glue that holds the city together... (Scott and Storper, 2015: 6).

... an assemblage is first and foremost what keeps very heterogeneous elements together... How do things take on consistency? How do they cohere? (Deleuze, 2007: 17).

Agglomeration: v. to gather into a cluster, mass or ball n. a mass or collection of things; an assemblage (Oxford Dictionary, 2016).

In two recent papers Storper and Scott have sought to counter the rise of assemblage thinking in urban critique (Scott and Storper, 2015; Storper and Scott, 2016). Among other things they suggest that such an approach is superficial, jargon-ridden, non-empirical and indeterminate; that it suffers from a fetish for the particular and lacks a critique of power or agency. In this critique assemblage thinking is combined and at times conflated with the closely aligned actor-network theory as well as the rather different postcolonial theories (Roy, 2011) and planetary urbanism (Brenner and Schmid, 2014). Against such approaches they posit a set of 'fundamental common genetic factors underlying urban patterns' that comprise the 'nature' of cities (Scott and Storper, 2015: 1115). At the heart of such genetic factors we find agglomeration:

...cities are everywhere characterised by agglomeration involving the gravitational pull of people, economic activities, and other relata into interlocking, high-density, nodal blocks of land use.... (Storper and Scott, 2016: 1116).

Gravity here is a metaphor for the economic forces that counter the friction of distance and tend towards dense urban agglomerations. Since urban activities can't simply multiply in the same space, 'they must necessarily sort themselves into a spatially extensive lattice or patchwork organized around their common centre of gravity' (Storper and Scott, 2016: 1116). In doing this urban agents are driven by a desire to get the benefits of urban proximity while avoiding negative effects. The economic benefits of agglomerating include the capacity to share infrastructure, to match up with collaborators and clients, and to learn about current ideas and techniques. The 
negative effects of congestion, crime and so on are then mediated by different forms of governance. The outcome - the agglomeration, the city - is defined as an 'urban land nexus'.

While we might quibble about some of the language here, we suggest that such thinking does not stand against assemblage thinking, rather it is largely compatible with it. By relying on selected reading of applications of assemblage approaches, Scott and Storper largely misconstrue what it is about, methodologically and ontologically. We suggest that many of the best parts of their own work could be understood as examples of assemblage thinking. The process of urban agglomeration is one of assemblage, and the urban land nexus is the assemblage that emerges from it. Key concepts introduced by Storper such as the morphogenic process of 'bundling' and the urban 'buzz' of face-to-face communication are also consistent with assemblage thinking.

Assemblage thinking is primarily developed from the philosophy of Deleuze, particularly his collaboration with Guattari on the book 'A Thousand Plateaus' (Deleuze and Guattari, 1987). This is one of the most jargonridden works one can imagine; Deleuze and Guattari share an aversion to coming to the point, often for good reason but to the frustration of the reader. Assemblage thinking is a practice of looking for relationships more than looking at things; seeking to understand how synergies and flows work. While Deleuze and Guattari made no claim to the status of theory, it has been developed as theory by DeLanda $(2006,2016)$ among others and applied in a burgeoning variety of ways in urban studies (Dovey, 2016; McFarlane, 2011; McGuirk et al., 2016; Müller, 2015; Rankin, 2011; Sendra, 2015; Simone, 2011; Wood, 2009). It has been variously identified with 'relational' (Jacobs, 2012), 'material' (Rydin, 2014) and 'non-representational' (Anderson and Harrison, 2010) turns in social theory. It has a 'flat ontology' that opposes the reduction of the particular to the general, of smaller to larger scales. Assemblage is a means of engagement with the world more than a formal theoretical discourse. One of its lessons is that a focus on theory as the end rather than the means of urban engagement can inhibit one's thinking.

We first respond to Storper and Scott's critiques of assemblage thinking before outlining a series of ways in which their work can be understood as compatible with assemblage thinking. Finally, we propose some ways in which assemblage thinking can enhance the quest for an open theory of urbanity that connects sciences and humanities, objectivity and subjectivity. Like the city itself assemblage thinking is multi-scalar and multidimensional; it connects the disciplines of geography and social theory with practices of architecture, planning and design, overturning hegemonies of scale and facilitating multi-scale thinking. It enables us to gear the economics of urban agglomeration to the study of urban morphology and informal urbanism. Assemblage thinking offers an account of the city as a synergy of density, mix and access. It opens up an understanding of 
the way in which a city embodies capacities for change - gearing the study of the actual city to its possible futures. While the larger project of Storper and Scott's papers is to argue for a general theory of cities, we argue that their exclusion of assemblage thinking runs counter to this goal.

\section{Critiques of assemblage thinking}

The critique mounted by Storper and Scott ranges across postcolonial thinking, planetary urbanism, actornetwork theory and assemblage theory. Within this critique assemblage thinking is partially confused with postcolonial thinking. While Deleuzian concepts are often used within postcolonial critique and many scholars combine the two approaches, there are also trenchant postcolonial critiques of Deleuzian thought. While both postcolonial and assemblage theories are anti-essentialist, assemblage thinking is a distinctive approach. In its desire to incorporate both materiality and representation - objective and subjective, sciences and humanities assemblage thinking is also not so far from the work of thinkers such as Benjamin, Lefebvre, Bourdieu and Giddens as is often imagined.

A key argument against assemblage theory is that the extensive use of jargon and neologism render it incomprehensible and indeterminate. On this point we largely agree. The use of an exclusive language plays a key part in insulating different modes of thought from each other. Learning the language is the price one must pay for admission to the club; use of a private language is a micro-practice of power that turns ideas into ideologies and defends them from attack. At the same time new language can be required for new ways of thinking. It may or may not be useful to invent neologisms like 'line of flight', 'smooth space' and 'body

without organs' - the key criterion is whether such jargon can become useful beyond the confines of the theory. In becoming difficult to understand, assemblage thinking also leaves itself vulnerable to the charge that it is indeterminate - that it lacks clarity. Deleuze and Guattari do have an aversion to determinacy and reductionism that can be frustrating, yet anti-reductionism is central to assemblage thinking. From their perspective philosophy is the invention of concepts as tools for thinking - assemblage is a conceptual toolkit (Massumi, 1987: xii). We should not be surprised when a new tool is given a new name and if it turns out to be useful then that name will find a common usage. The real test of assemblage thinking lies in the usefulness of new ways of thinking about cities that it opens up. Jargon needs to be translated as much as possible into an accessible language. Yet indeterminacy will remain since if concepts are tools then it follows that any concept can be useful for a limited but indeterminate range of tasks. While a hammer is of little use for digging a hole it can be used as a paperweight or a weapon. Once the point is nailed home then the tool can disappear along with the 
jargon; theory is the means rather than the end of assemblage thinking. While many scholars use urban research in order to make a theoretical point (as in this paper), the larger task of assemblage thinking is to use theory as the means to understand and transform the city.

Storper and Scott (2016: 1132) portray assemblage thinking as 'a conceptually barren search for difference, particularity and localism' where a focus on the particularities of the city precludes the emergence of a general theory of cities. This is a misunderstanding that stems from a desire to see the particulars of the city subsumed into a general theory of cities. While assemblage is a general theory, it is not a model of the world within which the particulars can be reduced to the general. The relations of particular to general within assemblage thinking are reciprocal. The particular is not an instance of the general, rather what becomes general emerges in part from the interactions of particulars. The charge of particularism is an argument for a reduction of the particular to the general, of micro-scale to macro-scale, of the street to the city. To portray assemblage as a 'search for difference' betrays a presumption that identity precedes difference; assemblage embodies a 'flat' ontology whereby the world is a field of differences from which identities emerge. Assemblage is not a search for particularity but for the general within the particular; it resists the hierarchy of identity over difference and of the general over the particular (Rydin, 2014).

The charge of particularism is linked to that of 'naive objectivism', first levelled at assemblage thinking by Brenner et al. (2011). This is the view that the focus on material particulars leaves us unable to distinguish between significant and insignificant urban issues, that the micro-scale materialities of the slum, for instance, do not help us understand the context of social marginalization (Brenner et al., 2011: 234). Again the complaint here is with the ontology of assemblage thinking which is 'flat' in the sense that it does not recognize a transcendent order to which the immanent world can be reduced. Assemblage thinking asks that we abandon the hegemony of scale - the presumption that the global subsumes the local. The charge of particularism often hits the mark by selecting particular examples of assemblage research where the trivial is portrayed as significant with little reason; however this is not characteristic of good assemblage thinking.

A key component of Storper and Scott's critique is that assemblage thinking lacks criticality, that it stands outside critiques of social justice, empowerment, oppression and emancipation. They suggest that:

One searches in vain in assemblage theory and urban research based on it to know what larger difference assemblages make, which assemblages are important and which are insignificant and fleeting, which are empowering and which are disempowering, and what kinds of policy interventions are most likely to bring 
about desired forms of social change (Storper and Scott, 2016: 1128).

Assemblage is a theory of power with its roots in the Foucaultian critique of power as embodied in micropractices, as distributed and capillary rather than simply held. The Foucaultian apparatus of the panopticon is a key source and model of an assemblage (Deleuze and Parnet, 2007), yet Deleuze and Guattari exploit this revolution in thinking about power for its emancipatory potential as well as a critique of discipline.

Storper and Scott (2016: 1127) criticize the focus of assemblage theory on networks of 'rhizomatic entanglements without underlying processes of structuration'. Likewise Tonkiss (2011: 584) argues: ‘Assemblage thinkers don’t go in for structure, but they see agency everywhere. In this sense, assemblage has decided one of the basic problems in social science firmly on the side of agency'. Deleuze and Guattari are indeed firmly on the side of the emancipatory potential of rhizomic agency. However, there is a great deal of what might be understood as structure within assemblage thinking where we find a set of resonating twofold concepts - rhizome/tree, smooth/striated, becoming/being, difference/identity. The twofold is not binary and the tree-like structure does not play a reductive role - assemblage focuses attention on the ways power is produced rather than simply held. A flat ontology does not means one does not recognize nor take hierarchy seriously, rather it is to refuse a legitimation of hierarchy based on transcendent ideals such as the hegemony of scale.

One of the more common complaints about assemblage thinking is that it attributes agency to the non-human world - to materials, things and spaces (Storper and Scott 2016: 1127). It is axiomatic to assemblage theory that power is distributed and embodied in material spatial arrangements. This is not a form of environmental determinism nor a displacement of human agency; it is a recognition that power is produced and practiced through the materiality and spatiality of the city. Whether we call this action of technologies, things, buildings and places on our lives a form of 'agency' is a moot point. The 'agency of materials' concept is primarily identified with actor-network theory and the provocative concept of the 'actant' (Latour, 2005). While there are many overlaps of actor-network theory and assemblage, they cannot be conflated. A key point is that power is capillary and is not simply held by human agents. Tonkiss (2011: 587) puts it well when she complains: 'Where power is capillary, it seems, the buck never stops'. This is of course a real problem - power is slippery and hidden - but it is not a problem of assemblage thinking that it exposes this to be the case. 


\section{Agglomeration as assemblage}

Here we move from considering Storper and Scott's critique of assemblage thinking to the suggestion that their work can be seen as compatible with such thinking. Within their critique they argue that 'Assemblage theory radically privileges the activity of assemblage itself' (Storper and Scott, 2016: 1126) - yet they radically privilege the activity of agglomeration. So how different are processes of assemblage and agglomeration? For Storper and Scott urban agglomeration is the force of attraction, likened to a gravitational pull, that creates cities. The result of such agglomerative process is the 'urban land nexus' which is largely a synonym for 'city': 'all cities throughout history are based on this fundamental process of agglomeration' (Storper and Scott, 2016: 1116). Agglomeration is a fundamentally economic process where concentration occurs because of the friction of distance. The advantages of clustering are portrayed as 'sharing' (the cost of infrastructure), 'matching' (the ease of making new contacts) and 'learning' (from current ideas and techniques).

We have no quarrel with the premise that economic production and exchange is the raison d'être for cities (Scott and Storper, 2015: 6). This does not mean cities can be reduced to economics; it explains the why and where of cities but it does not show how cities tick. The concept of the 'urban land nexus' - the outcome of the agglomerative process - is seen as the 'essential fabric of intra-urban space' (Scott and Storper, 2015: 8). It defines the city in terms of a cluster of interconnections on land. Two key metaphors used by Storper and Scott to explain the underlying forces of agglomeration are 'gravity' and 'glue'. Gravity suggests that urban density embodies its own attraction - that people, buildings and activities are attracted to existing concentrations. Glue suggests a stickiness that prevents dispersal once they are settled in place. Both are potentially useful metaphors. Urban density embodies a force somewhat like gravity where the greater the mass the greater the attraction, and once an urban morphology becomes settled and productive then it becomes 'sticky' and difficult to detach from (Markusen, 1996).

If there is a parallel concept to glue and gravity within assemblage thinking, it might be found in 'desire'. Like gravity, desire is a force of attraction between parts of an assemblage that is immanent or embodied in the materiality world. Desires are multiple, intersecting and often contradictory. The suburb emerges from desires to have daily access to the city without living in it. The desire for a 'room with a view' produces agglomerations of capital investment in particular urban morphologies (tall buildings) and topographies (waterfronts). Such desires - for access to jobs, views, status, sociality, profit and so on - are at once productive of the city and produced by it. Desire is neither subjective nor objective; it cannot be simply located in the view or those who desire it, rather it is a flow or relation. This is not to suggest a different kind of reductionism to 'flows of desire', only that 
agglomeration can be understood as a multiplicity of attractions beyond the useful metaphors of glue and gravity.

One of Storper's many contributions to urban studies has been to show the ways urban land markets agglomerate into 'bundles' of amenity (Storper and Manville, 2006). At one scale a hotel chain offers a bundle of housing, food, recreation, shopping and office facilities integrated under conditions of security and design quality. A neighbourhood also offers a bundle of amenities - housing, recreation, security, views, walkability, shopping, schools, access and sociality. Urban governance is also a bundle of different levels and jurisdictions of power and control (Storper, 2014). Bundling can be understood as a land-use mix, a mix of amenities, or a bundle of governance structures and regulations. Any urban location embodies a bundle of amenities and practices that can only be exchanged as a bundle - the things we desire cannot be disaggregated from those we might wish to avoid such as crime and congestion. This focus on bundling rather than things in themselves is an important form of relational thinking, however, Storper is curiously uncritical when it comes to the particularities of urban bundles. What we might call 'neoliberal bundling' operates to meet the market for a purified city in which the negatives have been largely expunged; in doing so it diminishes the very qualities of urbanity that are fundamental to its productivity - the random encounter with difference. A bundle is by definition a juxtaposition of differences, yet controlled bundles eliminate difference to varying degrees. The gated enclaves, shopping malls, hotels and so on involve the production of quasi-public bundles with a relatively high level of closure in both spatial and representation terms - lacking the urban intensity of everyday streetlife. When the disbenefits of public life are removed so is the urbanity. A parallel loss of intensity applies in the carbased city where access networks become accumulations of private cars rather than the agglomeration of crowds. Storper and Manville (2006) suggest that the bundle of urban amenities accessible within 30 minutes in central Manhattan is similar to that in Los Angeles. Yet such a claim ignores the productive intensity of face-toface encounter on the one hand and the costs of parking on the other. Urban intensity is based in difference and is highly reliant on public streetlife. Urban bundles that are produced in order to control difference also diminish intensity.

This lack of attention to streetlife intensity is curious because Storper has also been at the forefront of rethinking the economic role of face-to-face contact in the urban context (Storper and Venables, 2004). The question of why cities are thriving in a context of burgeoning telecommunications is answered through an affirmation of the economic importance of face-to-face encounter. Some parts of some cities produce the urban 'buzz' of an intensive learning environment with an economic value that cannot be replaced by 
telecommunications. The formation of trust in economic partnerships requires face-to-face contact. This argument is a continuation of Marshall's (1890) insight that cities produce 'something in the air' with an economic value beyond simply eliminating the friction of distance, forms of tacit knowledge that require faceto-face communication. This idea of 'buzz' has many synonyms and cousins: 'atmosphere', 'vitality', 'character', 'sense of place' are among them, but the generic term we might use here is 'urbanity' or urban ‘intensity'. This is an experiential phenomenon and while we might describe it in phenomenological terms we will simply be describing the result. The buzz of urban intensity is at once a product of the city - an attraction that is consumed - but also a form of production. Here we intersect with Lefebvre (1991) and his insights that urban space is at once a product and a form of production; that space is always at once perceived, conceived and lived. The value of face-to-face contact has to do with the loose ties of the urban community rather than the bonded social capital of the closed community. It is based not in the reassuring wave of the well-recognized neighbour but in the learning that comes from the encounter with difference - new ideas, new partners, new possibilities. Yet Storper's account of the face-to-face economy is strangely aspatial, as if land ownership, urban design and spatial segmentarity were somehow neutral to the economics of face-to-face encounter. It is uncritical of the privatization and purification of the city where capital markets kill the very forms of urbanity that attract it in the first place.

\section{Scale and morphology}

It is axiomatic to agglomeration thinking that agglomeration is much more than aggregation; the urban land nexus is a complex mix of relations between different ingredients. Cities are not 'cogs designed to fit into the bigger administrative machine of transnational enterprises' (Storper 1997: 9). Yet agglomeration thinking retains the presumption that the parts of cities are subsumed by the whole: that the larger scale trumps the smaller. While Duranton and Storper (2006: 6) suggest that 'the microfoundations of urban morphology' should be explored more, the gaze of geographers and economists tends to remain at the larger scale. The urban land nexus is a concept that operates primarily at metropolitan scale with urban districts and neighbourhoods as subsets that are reduced to the larger scale: 'just as neighbourhoods, slums, industrial quarters, etc., are distinctive and idiosyncratic socio-spatial articulations (albeit within the urban land nexus), so the urban land nexus itself is a distinctive socio-spatial articulation (within wider global or planetary space)' (Storper and Scott, 2016: 1130). Note that the smaller scale 'socio-spatial articulations' are not granted the status of an urban land nexus. The 
hegemony of macro-scale that so often prevails in both economic and geographic thinking is at odds with the flat ontology of assemblage thinking.

This issue can be usefully viewed through the lens of the work of Jacobs $(1961 ; 1969)$ which involved key breakthroughs in the understanding of both urban morphologies and economies. She first argued that urban morphology at street and neighbourhood scales are crucial to the creativity and productivity of cities; and later that innovation and import replacement were more crucial than geography or agriculture for metropolitan growth. While Jacobs contributed major insights into how cities work at different scales, she rarely connected these scales and multi-scalar thinking remains a key challenge. With a nod to Jacobs we suggest such a multiscalar nexus might be construed as the 'urban DMA' - a conjunction of density, mix and access (Dovey, 2016). Density is the concentrations of people, practices and buildings that have the effect of shrinking distances. Mix as the set of co-functioning synergies between people, practices and places; at once a social, functional and formal mix - a mix of mixes. Access as the capacity of infrastructure networks to facilitate flows at every scale between buildings, neighbourhoods and cities. To understand this nexus means understanding the city as a threedimensional and multi-scalar morphology - abandoning phrases such as 'land use' that are a legacy of modernist zoning into singular functions. This nexus of density, mix and access does not determine urban outcomes any more than human DNA determines who we are, but without them it is not a city.

Storper and Scott (2016: 1117) make the point that we need to discriminate between issues that are of and in cities - between those that are necessary to understanding how cities work and those that just happen to be manifest in an urban setting. Agglomeration is a characteristic of cities while poverty is an issue that, while firmly embedded in cities, has sources at a broader scale. This important distinction suggests that the particular morphologies that are characteristic of cities are taken seriously. Storper and Scott (2016: 1132) suggest that assemblage approaches: 'offer few or no insights as to the genetics of indurated spatial and institutional arrangements'. Such an understanding, however, is not helped by an ontology that privileges larger scale thinking. One example here lies in the challenge of engaging with urban informality. For Storper and Scott (2016) informal settlements of the global south are simply listed (as 'slums') alongside other neighbourhoods as constituent parts of any city. This is a case of not distinguishing between issues that are in and of the city informality is a mode of urban production with morphogenic processes different from those of the formal city, a different urban DMA. This is not to suggest that urban informality is not present in the global north, only that our understanding of such cities is utterly inadequate for engagement with the many dimensions of informal urbanism - slipperiness, micro-spatial incrementalism, camouflage and rhizomic adaptation (Dovey, 2012). 


\section{Towards an open theory of urbanity}

The larger project of Storper and Scott's papers is to argue for a general theory of cities and we would not contest such a goal so long as it is not an excuse to exclude new ways of thinking. In our view such a body of theory is emerging out of a mix of approaches including structuration, assemblage, agglomeration, complex adaptive systems, postcolonial and marxist critique. Assemblage is not a theory where all the parts fall into line with strict orthodoxy but rather a loose set of alliances between different modes of thought. This theoretical multiplicity is necessary in urban studies because the city is such a multiplicitous phenomenon that requires different modes of thought in order to understand the many different ways in which it operates. There is no sense in which we seek to place assemblage thinking at the centre of such a general theory of cities. It can be useful, however, in establishing the importance of all theories to remain open to alliances with each other.

The most potent criticism of assemblage thinking is the unnecessary jargon that leads to a mix of misunderstanding and incomprehension. We cannot expect to rid the field of jargon but any movement towards a general theory of urbanity needs a genuinely shared language for debate. Theories are forms of territory where intellectual capital is consolidated and protected along with the reputations of those who contribute or sign up. This is why boundaries between theories are constructed, partly through jargon but also through more direct discourses of exclusion - recognize this concept and not that one; invite or employ this and not that scholar; ask these and not those questions. But what if a theory suggests that multiplicitous thinking is precisely what is required in order to better understand cities? Assemblage is such a theory of multiplicity, of exploring the spaces between territories as a primary means of producing new ideas. With a nod to some other major relational thinkers in urban studies such as Massey’s (1994) 'open sense of place' and Sennett's (2007) concept of the 'open city', we might term this an open theory of urbanity.

Assemblage is a philosophy where the process of becoming takes priority over any stabilized sense of being, where the Heideggerian 'being-in-the-world' is replaced by a Deleuzian 'becoming-in-the-world' (Dovey, 2010: 6). It enables an understanding of the city in terms of both actual and possible worlds - the city as an assemblage of people, places and practices; at once a set of actual arrangements and a range of capacities for what it might become. This opens up a 'space of possibility' (DeLanda, 2016) - a capacity to become transformed, designed and planned in a range of different ways. Urban studies can become more closely geared to the creative and critical practices of architecture, urban design and the arts. Design research emerges as a field of research that is 
conducted through design; boundaries between research and practice erode as we experiment on the real city as the laboratory of urban studies (Thrift, 2011).

Assemblage thinking is grounded in the precept that difference precedes identity; that identities of places, people and institutions emerge from differences. The encounter with difference is at the heart of how cities work as productive learning assemblages. Thus an assemblage approach seeks to connect different categories of thought. It connects different scales enabling alliances between different built environment disciplines. It flattens hierarchies of scale and enables us to understand the ways micro- and meso-scale urban morphologies are geared to the economics of agglomeration. Assemblage thinking cuts across divisions between formal and informal urbanism, between top-down policy and everyday life, opening up understandings of incremental adaptation and emergence. Finally assemblage is productive of alliances between the sciences, humanities and arts together with their dominant modes of discourse - numbers, words and images respectively. The monopoly held for so long by numbers and words is eroded as maps and diagrams become potent forms of spatial knowledge (Dovey and Pafka 2016). New alliances can cut across divisions between spatiality and sociality; between materiality and meaning. It is easy to call this 'interdisciplinary' yet many theoretical territories are not 'disciplines' in the strict sense and assemblage thinking is relatively undisciplined. In the end the choice is not between agglomeration and assemblage, nor between different modes of thought, so much as between the singular and the multiple. What is most needed is not for more scholars to sign up to an assemblage approach, but for a deterritorialization of urban studies - more open and productive interfaces between disciplines and approaches. Assemblage is not a framework into which agglomeration fits, it is a mode of thinking through which a more open theory of urbanity becomes possible.

\section{References}

Anderson B and Harrison P (eds) (2010) Taking-Place. Surrey: Ashgate Publishing.

Brenner N, Madden DJ and Wachsmuth D (2011) Assemblage urbanism and the challenges of critical urban theory. City 15(2): 225-240.

Brenner N and Schmid C (2014) The 'Urban Age' in Question. International Journal of Urban and Regional Research 38(3): 731-755.

DeLanda M (2006) A New Philosophy of Society. London: Continuum.

DeLanda (2016) Assemblage Theory, Edinburgh: Edinburgh UP.

Deleuze G (2007) Two Regimes of Madness. London: MIT Press. 
Deleuze G and Guattari F (1987) A Thousand Plateaus. Minneapolis: University of Minnesota Press.

Deleuze G and Parnet C (2007) Dialogues II. New York: Columbia University Press.

Dovey K (2010) Becoming Places: Urbanism/Architecture/Identity/Power. London: Routledge.

Dovey K (2012) Informal settlement and complex adaptive assemblage. International Development Planning Review 34(3): 371-90.

Dovey K (2016) Urban Design Thinking. London: Bloomsbury.

Dovey K and Pafka E (2016) The Science of Urban Design? Urban Design International 21(1): 1-10.

Duranton G and Storper M (2006) Agglomeration and growth. Journal of Economic Geography 6(1): 1-7.

Giddens A (1990) The Consequences of Modernity. Cambridge: Polity Press.

Jacobs J (1961) The Death and Life of Great American Cities. New York: Random House.

Jacobs J (1969) The Economy of Cities. New York: Random House.

Jacobs JM (2012) Urban geographies I. Progress in Human Geography 36(3): 412-422.

Latour B (2005) Reassembling the Social. Oxford \& New York: Oxford University Press.

Lefebvre H (1991) The production of space. Oxford: Blackwell.

Markusen A (1996) Sticky places in slippery space. Economic Geography 72(3): 293-313.

Marshall A (1890) Principles of Economics. London: Mac-Millan.

Massey D (1994) Space, Place and Gender. Cambridge: Polity Press.

Massumi B (1987) Translator's Introduction. In: Deleuze G and Guattari F A Thousand Plateaus. London: Athlone, pp.ix-Xv.

McFarlane C (2011) The city as assemblage. Environment and Planning D, 29(4): 649-671.

McGuirk PM, Mee KJ and Ruming KJ (2016) Assembling urban regeneration? Geography Compass 10(3): 128-141.

Müller M (2015) Assemblages and actor-networks. Geography Compass 9(1): 27-41.

Oxford Dictionary (2016) Available at: http://www.oxforddictionaries.com/definition/english/agglomeration (accessed 27 June 2016).

Rankin KN (2011) Assemblage and the politics of thick description. City 15(5): 563-569.

Roy A (2011) Slumdog cities. International Journal of Urban and Regional Research 35(2): 223-238.

Rydin Y (2014) The challenges of the "material turn” for planning studies. Planning Theory and Practice 15(4): 590-595. 
Scott AJ and Storper M (2015) The nature of cities: The scope and limits of urban theory. International Journal of Urban and Regional Research 39(1): 1-15.

Sendra P (2015) Rethinking urban public space. City 19(6): 820-836.

Sennett R (2007) The Open City. In: Burdett R and Sudjic D (eds) The Endless City. London: Phaidon, pp.290298.

Simone A (2011) The surfacing of urban life. City 15(3-4): 355-364.

Storper M (1997) The city. The Service Industries Journal 17(1): 1-27.

Storper M (2014) Governing the large metropolis. Territory, Politics, Governance 2(2): 115-134.

Storper M and Manville M (2006) Behaviour, preferences and cities. Urban Studies 43(8): 1247-1274.

Storper M and Scott AJ (2016) Current debates in urban theory: A critical assessment. Urban Studies 53(6): 1114-1136.

Storper M and Venables AJ (2004) Buzz. Journal of Economic Geography 4(4): 351-370.

Thrift N (2011) Lifeworld Inc and what to do about it. Environment and Planning. D, 29(1): 5-26.

Tonkiss F (2011) Template urbanism. City 15(5): 584-588.

Wood S (2009) Desiring Docklands. Planning Theory 8(2): 191-216. 